\title{
Genetic correlations of mid-infrared-predicted milk fatty acid groups with milk production traits
}

\author{
A. Fleming, ${ }^{* 1}$ F. S. Schenkel, ${ }^{*}$ F. Malchiodi, ${ }^{*}$ R. A. Ali,† B. Mallard,‡ M. Sargolzaei, ${ }^{\star} \S ~ J . ~ J a m r o z i k,{ }^{*} \#$ \\ J. Johnston,\# and F. Miglior*\# \\ ${ }^{*}$ Centre for Genetic Improvement of Livestock, Department of Animal Biosciences, \\ †Department of Mathematics and Statistics, and \\ ‡Department of Pathobiology, University of Guelph, Guelph, ON, N1G 2W1, Canada \\ §Semex Alliance, Guelph, ON, N1H 6J2, Canada \\ \#Canadian Dairy Network, Guelph, ON, N1K 1E5, Canada
}

ABSTRACT

The objective of this research was to estimate the genetic correlations between milk mid-infrared-predicted fatty acid groups and production traits in first-parity Canadian Holsteins. Contents of short-chain, mediumchain, long-chain, saturated, and unsaturated fatty acid groupings in milk samples can be predicted using midinfrared spectral data for cows enrolled in milk recording programs. Predicted fatty acid group contents were obtained for 49,127 test-day milk samples from 10,029 first-parity Holstein cows in 810 herds. Milk yield, fat and protein yield, fat and protein percentage, fat-toprotein ratio, and somatic cell score were also available for these test days. Genetic parameters were estimated for the fatty acid groups and production traits using multiple-trait random regression test day models by Bayesian methods via Gibbs sampling. Three separate 8- or 9-trait analyses were performed, including the 5 fatty acid groups with different combinations of the production traits. Posterior standard deviations ranged from $<0.001$ to 0.01 . Average daily genetic correlations were negative and similar to each other for the fatty acid groups with milk yield $(-0.62$ to -0.59$)$ and with protein yield $(-0.32$ to -0.25$)$. Weak and positive average daily genetic correlations were found between somatic cell score and the fatty acid groups (from 0.25 to 0.36 ). Stronger genetic correlations with fat yield, fat and protein percentage, and fat-to-protein ratio were found with medium-chain and saturated fatty acid groups compared with those with long-chain and unsaturated fatty acid groups. Genetic correlations were very strong between the fatty acid groups and fat percentage, ranging between 0.88 for unsaturated and

Received November 3, 2017

Accepted January 11, 2018.

${ }^{1}$ Corresponding author: fleminga@uoguelph.ca
0.99 for saturated fatty acids. Daily genetic correlations from 5 to $305 \mathrm{~d}$ in milk with milk, protein yield and percentage, and somatic cell score traits showed similar patterns for all fatty acid groups. The daily genetic correlations with fat yield at the beginning of lactation were decreasing for long-chain and unsaturated fatty acid groups and increasing for short-chain fatty acids. Genetic correlations between fat percentage and fatty acids were increasing at the beginning of lactation for short- and medium-chain and saturated fatty acids, but slightly decreasing for long-chain and unsaturated fatty acid groups. These results can be used in defining fatty acid traits and breeding objectives.

Key words: fatty acid, production trait, genetic correlation, Gibbs sampling

\section{INTRODUCTION}

Interest is growing in broadening selection objectives in dairy cattle breeding to include novel traits to improve milk quality, cow health, and fertility so as to complement selection for production traits. The composition of milk fat is meaningful for human health and nutrition (Parodi, 2004), but also as a potential indicator for the metabolic and health status of the cow and novel traits such as energy balance and methane emissions (Jorjong et al., 2015; van Gastelen and Dijkstra, 2016). Emerging consumer concern over the health effects of the products they consume has elicited research into the possibility of altering the fatty acid content of milk. Bovine milk fat is a source of many fatty acids with potential health benefits (Parodi, 2004), and increased proportions of those fatty acids promoting good health may be a worthy breeding goal.

The fatty acid profile of milk can be altered through the feeding of specialized diets to lactating dairy cows (Palmquist et al., 1993; Chilliard et al., 2000; Kliem and Shingfield, 2016); however, these changes are only temporary and depend on feed availability and prices. 
Likewise, limitations exist to the amount of fat that can be fed to dairy cows and the availability of these dietary lipids to the mammary gland to be used for milk production (Kliem and Shingfield, 2016). The fatty acid composition of milk is also influenced by the genetics of the cow (Soyeurt et al., 2007; Stoop et al., 2008; Bastin et al., 2011; Pegolo et al., 2016), thus providing the possibility for genetic selection to permanently enhance the milk fatty acid profile for the entire cow population.

The implementation of a new trait into a selection program requires an affordable means of phenotyping the trait routinely on a large scale. Mid-infrared (MIR) spectroscopy is already used to record fat and protein percentage, MUN, and BHB contents in milk during routine milk recording. More recently, studies have shown that milk fatty acid contents can also be predicted from the MIR spectra of a milk sample (Soyeurt et al., 2006; Rutten et al., 2009; De Marchi et al., 2011; Fleming et al., 2017). The prediction of milk fatty acid contents using MIR technology facilitates the collection of large numbers of these phenotypes for all milk-recorded cows. Genetic evaluation and selection for these traits is thus achievable for the dairy industry. To avoid unwanted correlated responses with other important traits, knowledge of these genetic correlations is important before implementation of fatty acid composition traits into breeding goals. To our knowledge, no studies have investigated genetic correlations across the lactation between fatty acid groups and milk production traits in dairy cattle, with the exception of Bastin et al. (2011, 2013), who used daily EBV correlations to approximate genetic correlations between fatty acids and select milk traits. The objective of our study was to estimate the genetic correlations of milk fatty acid group contents with milk production traits in the Canadian Holstein population using multiple-trait animal models.

\section{MATERIALS AND METHODS}

\section{Data}

Milk MIR spectra obtained during routine milk recording from 1 of 2 MilkoScan FT6000 spectrometers
(Foss, Hillerød, Denmark) at CanWest DHI (Guelph, ON, Canada) or Valacta (Sainte-Anne-de-Bellevue, QC, Canada) milk laboratories were stored in a database. Spectra were collected between January 2013 and July 2015 and standardization of spectra between the 2 machines was performed per Bonfatti et al. (2017). The database contained a total of 2,053,396 spectra of individual milk samples from Holstein cows.

Prediction equations developed by Fleming et al. (2017) for 5 groups of fatty acids, expressed as grams per deciliter of milk, were applied to the historical spectra. Fatty acid groups were defined by saturation (SFA and UFA) and by chain length [short-chain (SCFA; 4 to 10 carbons), medium-chain (MCFA; 11 to 16 carbons), and long-chain (LCFA; 17 to 22 carbons)]. The individual fatty acids used to devise the groups are given in Table 1. Fatty acid contents were examined on a per-milk basis instead of on a per-fat basis because of the greater prediction accuracies achieved. The coefficients of determination of cross-validation for the prediction equations were $0.94,0.84,0.72,0.90$, and 0.83 for the SFA, UFA, SCFA, MCFA, and LCFA groups, respectively. Fatty acid predictions were deleted for samples with MIR spectral data considered as outliers and dissimilar to those used to develop the calibrations. Spectral outliers were determined using the root mean square error for standardized predictors, calculated when the prediction equations by Fleming et al. (2017) were applied. Sample spectra with a mean square error greater than 3 standard deviations above the mean value were considered outliers and removed. All 5 groups of fatty acids were predicted for 1,957,353 Holstein milk samples with spectra saved in the database. Test day production records included milk, fat, and protein yields, SCC, and fat to protein ratio $(\mathbf{F}: \mathbf{P})$ and were obtained from the Canadian Dairy Network (Guelph, ON, Canada) for the test-day records with fatty acid contents predicted. The SCC was log-transformed to SCS according to the formula proposed by Ali and Shook (1980). The total number of milk samples with predicted fatty acid contents, along with complete testday production records and lactation information for the corresponding test-day, was 1,780,089 from 514,795 Holstein cows in 6,768 herds.

Table 1. Individual fatty acids included in the defined short-chain (SCFA), medium-chain (MCFA), long-chain (LCFA), SFA, and UFA groups of fatty acid traits

\begin{tabular}{|c|c|}
\hline Trait & Fatty acids included \\
\hline SCFA & $\mathrm{C} 4: 0, \mathrm{C} 6: 0, \mathrm{C} 8: 0, \mathrm{C} 10: 0$ \\
\hline MCFA & C11:0, C12:0, C13:0, C14:0, C14:1, C15:0, C16:0, C16:1 \\
\hline LCFA & C17:0, C17:1, C18:0, C18:1n-9 trans, C18:1n-9 cis, C18:2n-6 trans, C18:2n-6 cis, C18:3n-3, C18:2n cis-9, cis-12, C22:6n-3 \\
\hline SFA & C4:0, C6:0, C8:0, C10:0, C11:0, C12:0, C13:0, C14:0, C15:0, C16:0, C17:0, C18:0 \\
\hline UFA & C14:1, C16:1, C17:1, C18:1n-9 trans, C18:1n-9 cis, C18:2n-6 trans, C18:2n-6 cis, C18:3n-3, C18:2n cis-9, cis-12, C22:6n-3 \\
\hline
\end{tabular}


The imposed data restrictions and edits for the genetic analysis were the same as those defined by Narayana et al. (2017). In brief, only test-day records between 5 and 305 DIM of first-parity cows calving between 19 and 43 mo of age were considered. Included cows were required to be from herds with at least 70 cows and to have had their first test-day record within the first $50 \mathrm{~d}$ of lactation. A minimum of 4 records per herd on a test day was required. Strict data restrictions were required due to the low density of test-day records with fatty acid records in the full data set. Only a small proportion (approximately 15\%) of milk samples collected during milk recording had their MIR spectra outputted because only 2 of 12 milk spectrometers in Canadian DHI currently have these capabilities. The process by which milk samples were selected to go through these lines and have spectra collected was random. The final edited data set consisted of 49,127 test-day records from 10,029 first-parity Holstein cows from 810 herds. The number of test days per cow ranged from 4 to 10 and averaged approximately 4.9 test days per cow. A full pedigree file, going back as many generations as available, containing 76,074 individuals was provided by the Canadian Dairy Network.

\section{Model}

Three separate 8- or 9-trait random regression test day models were used for the genetic analysis. The 3 analyses were performed for the following combinations of traits: (1) 5 fatty acid groups, milk, fat, and protein yield, and SCS; (2) 5 fatty acid groups, milk yield, fat and protein percentage, and SCS; and (3) 5 fatty acid groups, milk yield, F:P, and SCS. Groupings were constructed to include the 5 fatty acids, milk yield, SCS, and 1 of the 3 different ways of expressing fat and protein. The model used for the genetic analyses was developed and described by Narayana et al. (2017). The model considered for all traits can be expressed in matrix notation by the equation

$$
\mathbf{y}=\mathbf{X}_{\mathrm{c}} \mathbf{c}+\mathbf{X}_{\mathrm{b}} \mathbf{b}+\mathbf{Z}_{\mathbf{h}} \mathbf{h}+\mathbf{Z}_{\mathrm{a}} \mathbf{a}+\mathbf{Z}_{\mathrm{p}} \mathbf{p}+\mathbf{e},
$$

where $\mathbf{y}$ is a vector of observations; $\mathbf{c}$ is a vector of fixed class effects of herd test day and DIM (300 classes) effects; $\mathbf{b}$ is a vector of fixed regression coefficients for age-season of calving effects (4 seasons and 25 age classes); $\mathbf{h}$ is a vector of random regression coefficients for herd year of calving effects; $\mathbf{p}$ is a vector of random regression coefficients for permanent environment effects; $\mathbf{a}$ is a vector of random regression coefficients for animal genetic effects; $\mathbf{e}$ is a vector of residuals; and $\mathbf{X}_{\mathbf{c}}$, $\mathbf{X}_{\mathrm{b}}, \mathbf{Z}_{\mathrm{h}}, \mathbf{Z}_{\mathrm{a}}$, and $\mathbf{Z}_{\mathrm{p}}$ are incidence matrixes assigning observations to effects.
Regression curves were modeled using orthogonal Legendre polynomials of order 4 for the fixed age season of calving effect, and using orthogonal Legendre polynomials of order 5 for the random effects as defined by Jamrozik et al. (2002). Expectations and covariance structure for the random effects were given by

$$
\begin{aligned}
& \mathbf{E}(\mathbf{y})=\mathbf{X}_{\mathbf{c}} \mathbf{c}+\mathbf{X}_{\mathbf{b}} \mathbf{b}, \mathbf{E}(\mathbf{h})=0 \\
& \mathbf{E}(\mathbf{a})=0, \mathbf{E}(\mathbf{p})=0, \mathbf{E}(\mathbf{e})=0
\end{aligned}
$$

and

$$
\begin{gathered}
\mathbf{V}(\mathbf{h})=\mathbf{I} \otimes \mathbf{Q}_{0}, \mathbf{V}(\mathbf{a})=\mathbf{A} \otimes \mathbf{G}_{0} \\
\mathbf{V}(\mathbf{p})=\mathbf{I} \otimes \mathbf{P}_{0}, \mathbf{V}(\mathbf{e})=\mathbf{E}
\end{gathered}
$$

where $\mathbf{I}$ is the identity matrix; $\mathbf{A}$ is the additive relationship matrix; $\mathbf{Q}_{0}$ is a (co)variance matrix for herd year regression coefficients; $\mathbf{G}_{0}$ is a (co)variance matrix of genetic regression coefficients; $\mathbf{P}_{0}$ is a (co)variance matrix for permanent environment regression coefficients; $\mathbf{E}$ is a block-diagonal residual (co)variance matrix; and $\otimes$ is the Kronecker product operator. Residual (co)variances were assumed heterogeneous across 20 intervals of 15 DIM ( 5 to 20,21 to 35,36 to $50, \ldots 291$ to 305 DIM). Residual correlations among traits on the same test day were allowed to be correlated. All residual correlations among traits on different test days were assumed to be 0 . All random effects were assumed to be normally distributed.

Variance components were estimated by Bayesian methods via Gibbs sampling using custom-written Fortran software. Flat prior values were assumed for all fixed effects. For genetic, herd year of calving, and permanent environment effects, normal prior distributions were used. Priors for variances and covariances were set according to preliminary estimates based on the same data. Posterior means of (co)variance components were estimated using 365,000 samples, where 30,000 constituted burn-in for each multiple-trait model. Visual inspection of trace plots for selected covariance was performed to monitor convergence. Daily heritability was defined as the ratio of genetic variance to the sum of genetic, permanent environment, herd year of calving, and residual variances, for each DIM from 5 to 305 , and averaged across the entire lactation. Because the fatty acid groups, milk yield, and SCS traits were included in all analyses, 3 average daily heritabilities were calculated and averaged to produce the overall average daily heritability. Average daily genetic correlations among traits were calculated using (co)variances of the first regression coefficients as described by Wood et al. (2003). The daily and average daily genetic cor- 
Table 2. Descriptive statistics of test-day records in the edited data set $(\mathrm{n}=49,127)$ for short-chain (SCFA), medium-chain (MCFA), long-chain (LCFA), SFA, and UFA groups; milk, fat, and protein yield; fat and protein percentage; fat-to-protein ratio (F:P); and SCS

\begin{tabular}{lrccc}
\hline Trait & Mean & SD & Minimum & Maximum \\
\hline SCFA (g/dL) & 0.41 & 0.08 & 0.08 & 0.85 \\
MCFA (g/dL) & 2.09 & 0.39 & 0.52 & 4.66 \\
LCFA (g/dL) & 1.40 & 0.32 & 0.36 & 4.07 \\
SFA (g/dL) & 2.81 & 0.47 & 0.70 & 3.23 \\
UFA (g/dL) & 1.10 & 0.24 & 0.31 & 72.90 \\
Milk (kg) & 30.29 & 6.27 & 6.00 & 2.87 \\
Fat (kg) & 1.18 & 0.25 & 0.20 & 2.14 \\
Protein (kg) & 0.97 & 0.18 & 0.22 & 8.00 \\
Fat (\%) & 3.96 & 0.63 & 0.84 & 2.72 \\
Protein (\%) & 3.23 & 0.31 & 0.30 & 9.64 \\
F:P & 1.23 & 0.18 & -3.64 & \\
SCS & 2.00 & 1.67 & & \\
\hline
\end{tabular}

relations between the fatty acid groups and milk yield and SCS were averaged across the 3 analyses.

\section{RESULTS AND DISCUSSION}

\section{Phenotypic Description}

Descriptive statistics of the fatty acid groups and production traits of the edited data set are given in Table 2. The raw phenotypic correlations between the fatty acid groups and the production traits are given in Table 3. Phenotypically, the fatty acid contents were most strongly correlated with fat percentage. The fatty acid contents are expressed on a per-milk basis and are therefore most similar to fat percentage, which is the amount of total milk fat in the milk by weight. In general, similar phenotypic correlations with the production traits were noted for SCFA, MCFA, and SFA and for LCFA and UFA. Most SFA are also in the SCFA or MCFA groups, whereas the majority of UFA are also included in the LCFA group, as shown in Table 1.

\section{Heritabilities}

The average daily heritabilities of the fatty acid groups and the analyzed production traits are displayed in Table 4. Higher average daily heritabilities were estimated for SCFA and MCFA compared with LCFA and for SFA in comparison to UFA. On a biological basis, it was anticipated that the de novo-synthesized SCFA and MCFA would be more heritable than the dietaryand adipose-derived LCFA in milk. The heritabilities of the fatty acid groups are greater, especially SCFA, than those estimated by Narayana et al. (2017), who used the same animals and model but a log-transformed MIR predicted fatty acids. The estimates in the present study are more in line with those found by Bastin et al. (2011). The estimated heritabilities for milk, fat, and protein yield and fat and protein percentages are lower than those previously estimated for first-parity Canadian Holsteins (Miglior et al., 2007; Loker et al., 2012). The heritability for SCS estimated in the present study was 0.049 , which is also lower than the 0.189 reported by Miglior et al. (2007) and the 0.15 reported by Loker et al. (2012). These discrepancies may be a function of the model used or differences in the data sets. In the current data set, a limited number of test days were available for some animals because MIR spectra were being recorded for only a limited proportion of all milk samples during DHI milk recording; therefore, the traits may not have been as well modeled across the lactation.

Table 3. Phenotypic correlations ${ }^{1}$ for short-chain (SCFA), medium-chain (MCFA), long-chain (LCFA), SFA, and UFA groups; and milk, fat, and protein yield; fat and protein percentage; fat-to-protein ratio (F:P); and SCS

\begin{tabular}{lccccccc}
\hline Item & $\begin{array}{c}\text { Milk } \\
\text { yield }\end{array}$ & $\begin{array}{c}\text { Fat } \\
\text { yield }\end{array}$ & $\begin{array}{c}\text { Protein } \\
\text { yield }\end{array}$ & Fat $\%$ & Protein $\%$ & F:P & SCS \\
\hline SCFA & -0.27 & 0.29 & -0.06 & 0.76 & 0.48 & 0.51 & 0.04 \\
MCFA & -0.31 & 0.26 & -0.06 & 0.78 & 0.58 & 0.46 & NS \\
LCFA & -0.19 & 0.27 & -0.21 & 0.62 & NS & 0.70 & 0.14 \\
SFA & -0.33 & 0.31 & -0.10 & 0.88 & 0.54 & 0.60 & 0.03 \\
UFA & -0.19 & 0.26 & -0.20 & 0.63 & 0.05 & 0.67 & 0.14 \\
\hline
\end{tabular}

${ }^{1}$ Presented correlations are significant at $P<0.0001$. 
Table 4. Average daily $\mathrm{h}^{2}$ and posterior standard deviations (PSD) of short-chain (SCFA), medium-chain (MCFA), long-chain (LCFA), SFA, and UFA groups; milk, fat, and protein yield; fat and protein percentage; fat-to-protein ratio $(\mathrm{F}: \mathrm{P})$; and SCS

\begin{tabular}{lcc}
\hline Trait & $\mathrm{h}^{2}$ & PSD \\
\hline SCFA & 0.420 & 0.007 \\
MCFA & 0.499 & 0.011 \\
LCFA & 0.261 & 0.003 \\
SFA & 0.509 & 0.011 \\
UFA & 0.264 & 0.004 \\
Milk yield & 0.274 & 0.013 \\
Fat yield & 0.218 & 0.003 \\
Protein yield & 0.230 & 0.009 \\
Fat \% & 0.505 & 0.016 \\
Protein \% & 0.524 & 0.009 \\
F:P & 0.321 & 0.004 \\
SCS & 0.049 & 0.001 \\
\hline
\end{tabular}

\section{Genetic Correlations}

The average genetic correlations between fatty acid groups and production traits are shown in Table 5 . Posterior standard deviations for average daily genetic correlations ranged from $<0.001$ to 0.01 . For each production trait, the 5 fatty acid groups displayed genetic correlations of the identical sign and of similar magnitude, although differences were still present. Narayana et al. (2017) previously reported strong genetic correlations between groups of fatty acids (from 0.63 to 0.96 ). These strong genetic correlations explain the similarity of the genetic correlations observed for the different fatty acid groups with production traits.

Overall, the strongest genetic correlations were observed between the fatty acid groups and fat percentage. Of the fatty acid groups, SFA and MCFA had the strongest genetic correlation with fat percentage at 0.990 and 0.982 , respectively. The genetic correlation between UFA and fat percentage was lower at 0.876 . Penasa et al. (2015) also found that SFA were more strongly correlated with fat percentage than UFA (0.991 vs. 0.838). They further divided UFA into MUFA and PUFA groups and found that MUFA were more strongly genetically correlated with fat percentage than PUFA. The different groups of fatty acids analyzed were simply defined as proportions of the total fat in the milk, so a strong genetic correlation was observed between the fatty acid groups and total milk fat percentage. The genetic correlations for fat percentage with milk yield, protein percentage, and SCS are also given in Table 5 for comparison purposes. The observed genetic correlations for milk yield, protein percentage, and SCS with fat percentage were similar to those found for the fatty acid groups, although somewhat stronger.

The genetic correlations for the fatty acid groups with milk yield were all negative, due to the effect of dilution, and similar to each other, ranging from -0.585 for SCFA to -0.615 for SFA. Negative genetic correlations were also found between the groups of fatty acids and protein yield, with correlations being similar for all fatty acid groups but strongest at -0.318 between LCFA and protein yield. Genetic correlations with protein percentage were moderate to strong and went from 0.638 for LCFA to 0.713 for MCFA. Genetic correlations between fatty acid groups and $\mathrm{F}: \mathrm{P}$ were again positive and moderate to strong in size. This trait is a function of fat and protein contents and thus displayed similar results to those traits.

Bastin et al. (2011) approximated genetic correlations using EBV correlations between fatty acid groups and protein yield and found these correlations to be negative, as we did. Similarly, they also found the strongest genetic correlation of the fatty acid groups with LCFA $(-0.27)$. The genetic correlations for protein percentage reported by Penasa et al. (2015) were lower than our findings, at 0.601 and 0.566 for SFA and UFA, respectively. For groups of fatty acids, the range in genetic correlations with protein percentage from Bastin et al. (2011) were from 0.38 for LCFA to 0.60 for PUFA, again lower than the range found in the present study.

The genetic correlations with SCS were, in general, moderately weak and positive (0.249 to 0.356). Bastin

Table 5. Average daily genetic correlations ${ }^{1}$ between short-chain (SCFA), medium-chain (MCFA), long-chain (LCFA), SFA, and UFA groups and milk, fat, and protein yield; fat and protein percentage; fat-to-protein ratio $(\mathrm{F}: \mathrm{P})$; and SCS

\begin{tabular}{|c|c|c|c|c|c|c|c|}
\hline Item & $\begin{array}{c}\text { Milk } \\
\text { yield }^{2}\end{array}$ & $\begin{array}{l}\text { Fat } \\
\text { yield }\end{array}$ & $\begin{array}{c}\text { Protein } \\
\text { yield }\end{array}$ & Fat $\%$ & Protein $\%$ & $\mathrm{~F}: \mathrm{P}$ & $\mathrm{SCS}^{2}$ \\
\hline SCFA & -0.585 & 0.499 & -0.248 & 0.959 & 0.697 & 0.819 & 0.249 \\
\hline MCFA & -0.611 & 0.497 & -0.270 & 0.982 & 0.713 & 0.842 & 0.286 \\
\hline LCFA & -0.609 & 0.415 & -0.318 & 0.915 & 0.638 & 0.800 & 0.345 \\
\hline SFA & -0.615 & 0.503 & -0.284 & 0.990 & 0.700 & 0.864 & 0.284 \\
\hline UFA & -0.598 & 0.377 & -0.277 & 0.876 & 0.683 & 0.713 & 0.356 \\
\hline Fat $\%$ & -0.667 & - & - & - & 0.721 & - & 0.341 \\
\hline
\end{tabular}

${ }^{1}$ Posterior SD ranged from $<0.001$ to 0.01 .

${ }^{2}$ Genetic correlations with fatty acid groups are the average of the 3 analyses. 
et al. (2013) approximated daily genetic correlations between SCS and fatty acid contents from pairwise regressions among EBV and found very weak genetic associations between the 2. Their genetic correlations between groups of fatty acids and SCS were averaged across DIM and the first 3 parities and ranged from -0.08 to 0.03 . The higher genetic correlations found in the present study are likely related to the high genetic correlation between fat percentage and SCS that was also found (0.341). Miglior et al. (2007) and Loker et al. (2012) both reported negative average daily genetic correlations between fat percentage and SCS in the first parity for Canadian Holsteins $(-0.161$ and -0.08 , respectively).

\section{Daily Genetic Correlations}

The genetic correlations between the fatty acid groups and production traits were not constant across the lactation. The trends for the daily genetic correlations throughout the lactation with the fatty acid groups are shown for each examined production trait in Figures 1 through 7 . The course of the genetic correlations across the lactation for the fatty acid groups with any given production trait were most similar between MCFA and SFA and between LCFA and UFA. Again, this was due to strong genetic correlations with each other and the similar makeups of the groups. The differences in the genetic correlations observed for the groups were also due to the distinct origins of the fatty acid groups. The SCFA and the majority of the MCFA are synthesized in the mammary gland de novo, whereas LCFA are provided to the mammary gland from blood lipids sourced from the diet or adipose tissues. Daily genetic correlations with total fat percentage are also displayed for milk yield, protein percentage, and SCS. Fat percentage tended to follow a similar pattern as the fatty acid contents.

Figure 1 shows the daily genetic correlations across the lactation for milk yield with all fatty acid groups and total fat percentage. At the beginning of lactation the genetic correlations were all weak and proceeded to become more negative until approximately d 105, where values started to level off. With milk yield, all of the fatty acids displayed similar patterns in genetic correlations as the lactation progressed, although correlations were stronger for SCFA, MCFA, and SFA than for the other groups at the beginning of lactation. Daily genetic correlations approximated from the correlation between daily EBV for 10 individual fatty acids, total PUFA, and fat percentage with milk yield were shown by Bastin et al. (2011) for first-parity Holsteins in Belgium. Although those authors did not group the fatty acids, a similar pattern to that found in the present study across the lactation was observed. Bastin et al. (2011) observed daily genetic correlations closest to zero at the beginning of lactation, before correlations became more negative for the majority of the fatty acids; this pattern was more notable for the individual LCFA examined. At the beginning of lactation, Bastin et al. (2011) found positive, although very weak, genetic correlations between C18:1n-9 cis and milk yield, which is similar to the genetic correlations between LCFA and UFA with milk yield in the present study. Similar results were also presented by Bastin et al. (2013) with daily genetic correlations estimated from the pairwise regression of EBV.

Figure 2 shows the genetic correlations between fat yield and fatty acid groups. At the beginning of lactation, LCFA and UFA had genetic correlations of approximately 0.78 and 0.76 with fat yield, respectively. From this initial point, their genetic correlations then decreased for the majority of the lactation before increasing slightly after 255 DIM. Correlations for SCFA, MCFA, and SFA had lower correlations at the start of lactation $(0.42,0.66$, and 0.70 , respectively), but then showed an increase in the first stage of lactation for SCFA and were more stable for MCFA and SFA. These fatty acid groups displayed weakening genetic correlations with fat yield after approximately 105 DIM.

Analogous findings are also shown in Figure 3 for fat percentage with fatty acid groups. In the initial part of the lactation, correlations with SCFA, MCFA, and SFA increased until approximately 55 to 105 DIM. In contrast, LCFA and UFA remained relatively constant, with a slight decline during this phase of lactation. At the end of lactation, all groups of fatty acids display a decrease in their genetic correlations with fat percentage. In the beginning of lactation, cows are in a state of negative energy balance and there is an increase in the mobilization of body reserves to meet the demands of lactation. As a result, increased amounts of LCFA, which originate from dietary and adipose lipids, are incorporated into the milk fat (Stoop et al., 2009). Therefore, variations in the fatty acid contents at the beginning of lactation may be indicative of the physiological status of the cow. The genetic correlations observed at the first stage of lactation may reflect these changes occurring in the cow during this phase, and thus the beginning of lactation is a crucial period to examine in depth. In this stage, LCFA was found to have a greater genetic correlation with both fat yield and percentage than the other fatty acid groups did. Selection for total fat at this time point may therefore have a greater effect on LCFA contents than other fatty acids. Energy balance has implications for the health and future reproductive performance of the cow (Ingvartsen et al., 2003; Jorritsma et al., 2003; Pryce et 


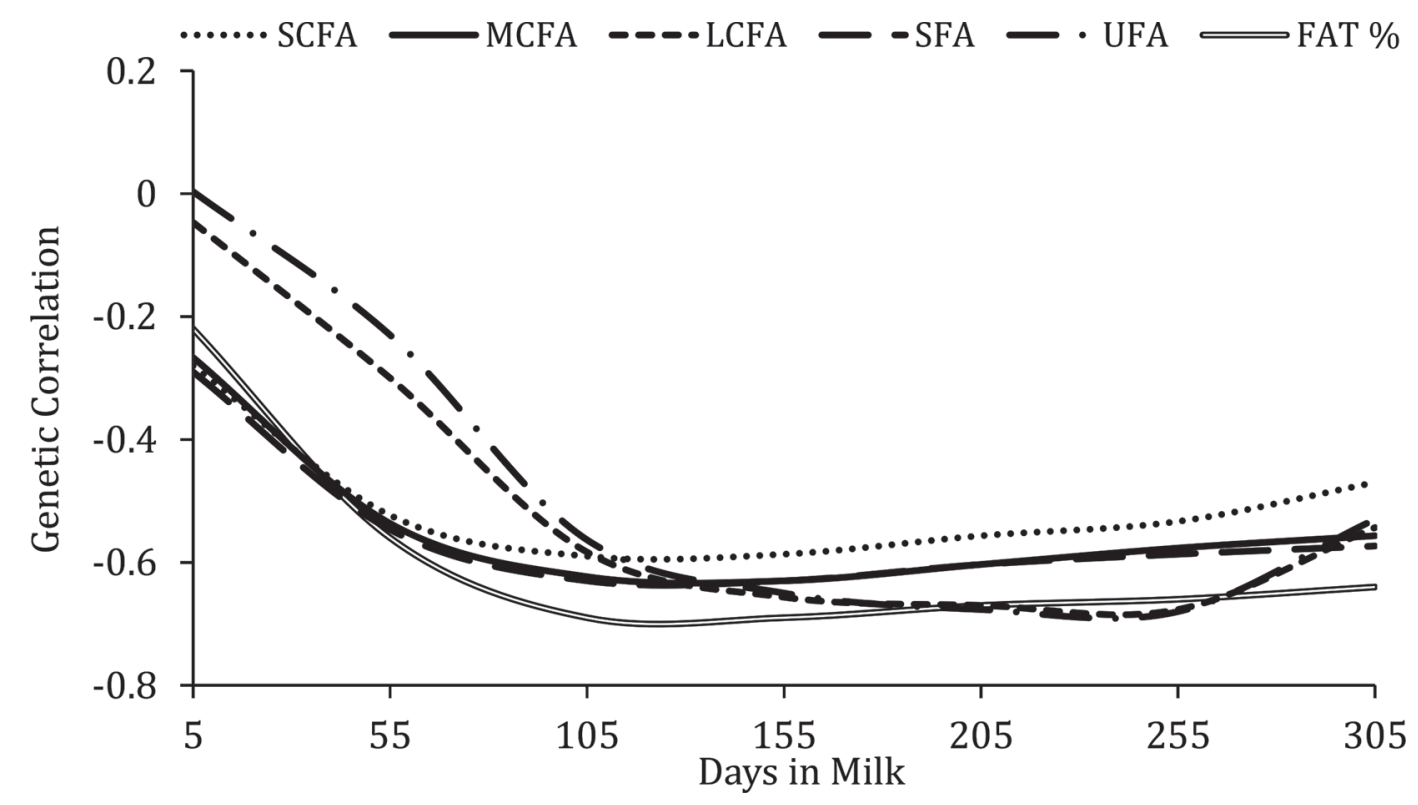

Figure 1. Daily genetic correlations for short-chain (SCFA), medium-chain (MCFA), long-chain (LCFA), SFA, and UFA groups averaged across the 3 analyses as well as fat percentage (FAT \%) with milk yield.

al., 2004), and therefore breeders should be mindful of genetic correlations in early lactation when conducting selection.

Throughout the lactation, the trend observed for the genetic correlations with protein yield (Figure 4) and protein percentage (Figure 5) were similar for all of the fatty acid groups. For protein yield, correlations were generally weak throughout the lactation but were strongest and negative in mid to late lactation. Genetic correlations between the fatty acid groups and protein percentage were the strongest in mid lactation and closer to zero at the beginning stage, approximately mirroring the correlation pattern observed between fatty acids and milk yield. The greatest difference in magnitude

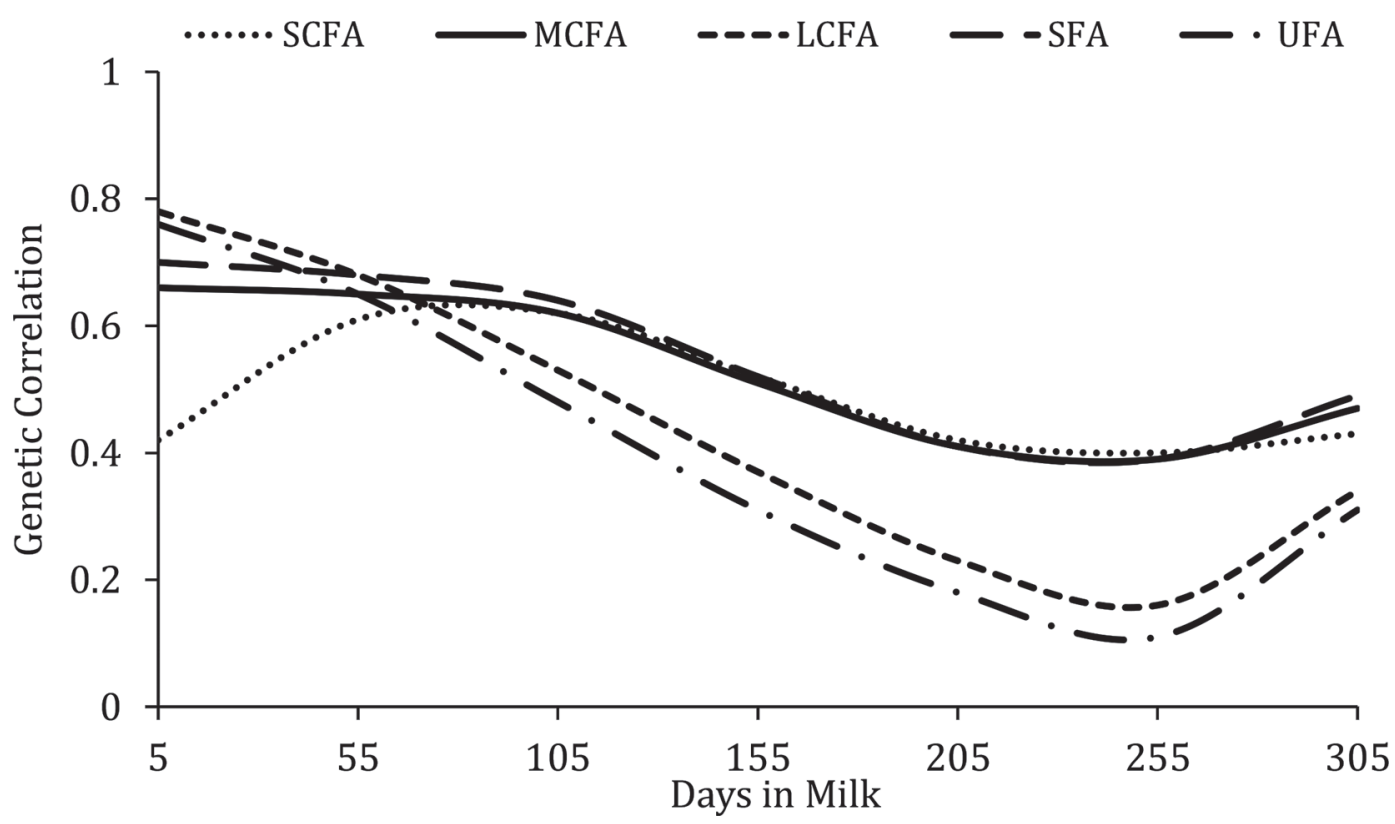

Figure 2. Daily genetic correlations for short-chain (SCFA), medium-chain (MCFA), long-chain (LCFA), SFA, and UFA groups with fat yield. 


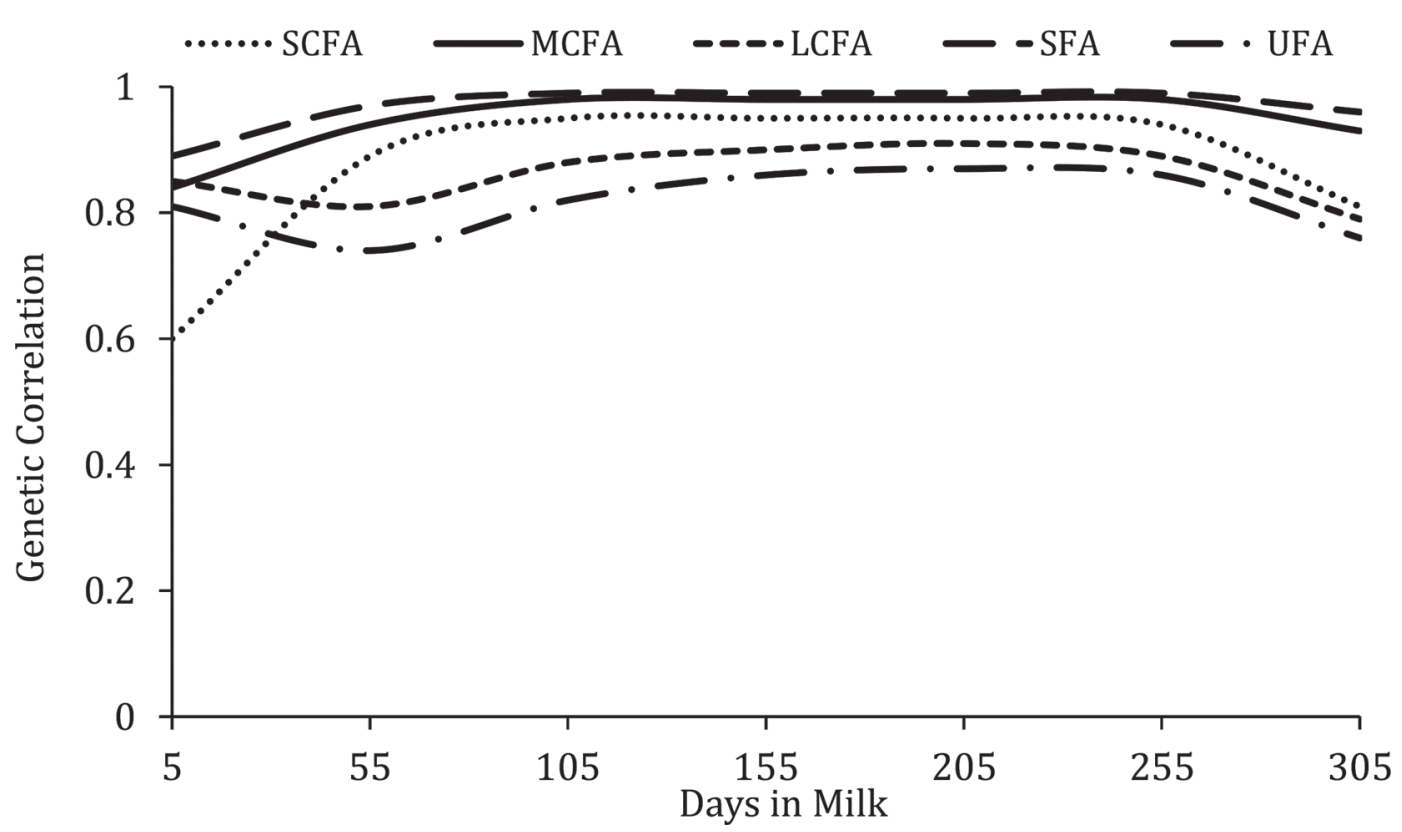

Figure 3. Daily genetic correlations for short-chain (SCFA), medium-chain (MCFA), long-chain (LCFA), SFA, and UFA groups with fat percentage.

occurred within the initial stage of lactation, where the genetic correlations for protein percentage with LCFA and SFA were closer to zero than the remaining groups of fatty acids. In mid and late lactation, genetic correlation became more similar among the fatty acid groups. The general trend observed for the genetic correlations across the lactation for the fatty acid groups was similar to the trend between fat and protein percentages.

The daily genetic correlations of F:P with fatty acid groups are displayed in Figure 6. The observed trends are related to the genetic correlations between the fatty acids and total fat content. For LCFA and UFA, the ge-

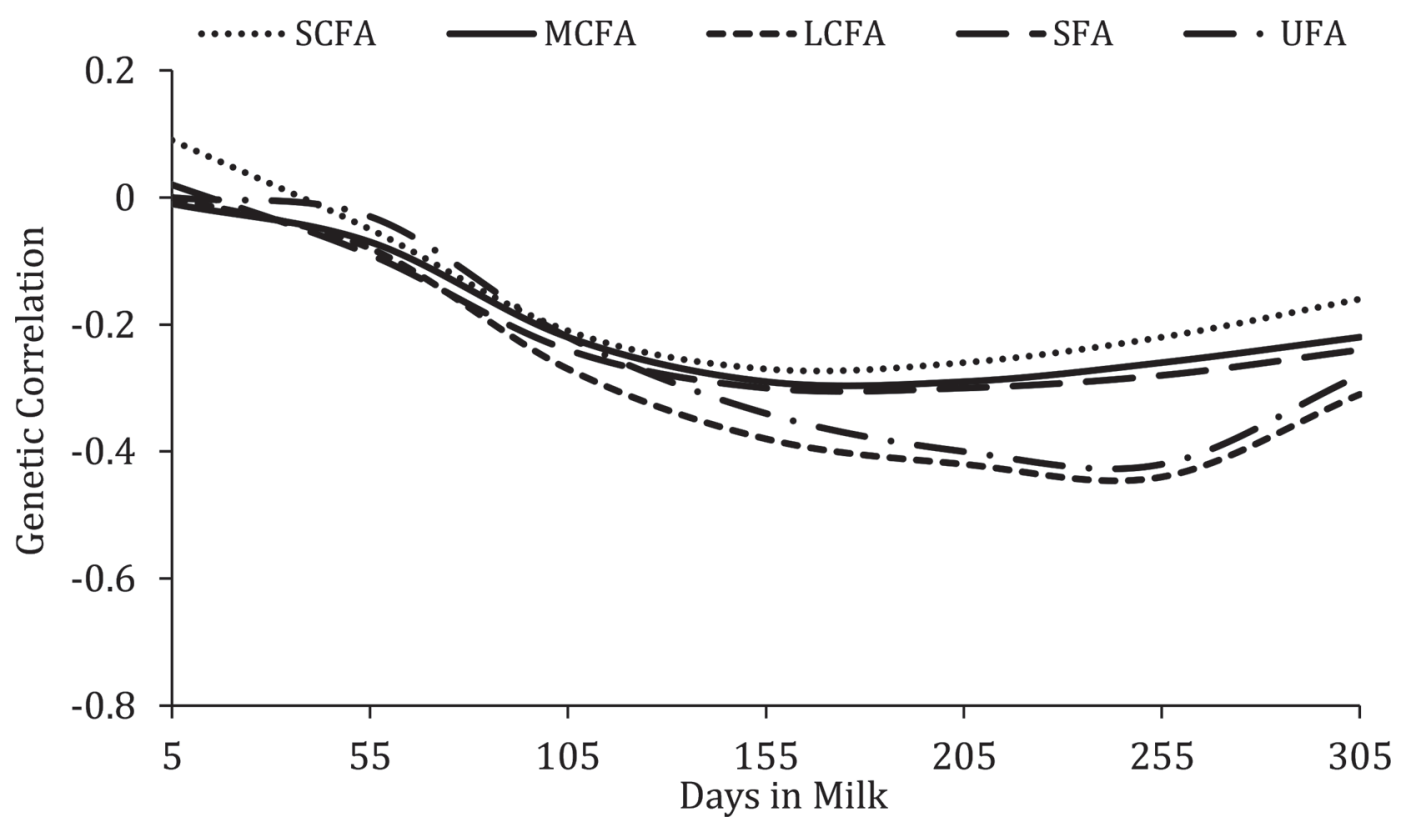

Figure 4. Daily genetic correlations for short-chain (SCFA), medium-chain (MCFA), long-chain (LCFA), SFA, and UFA groups with protein yield. 


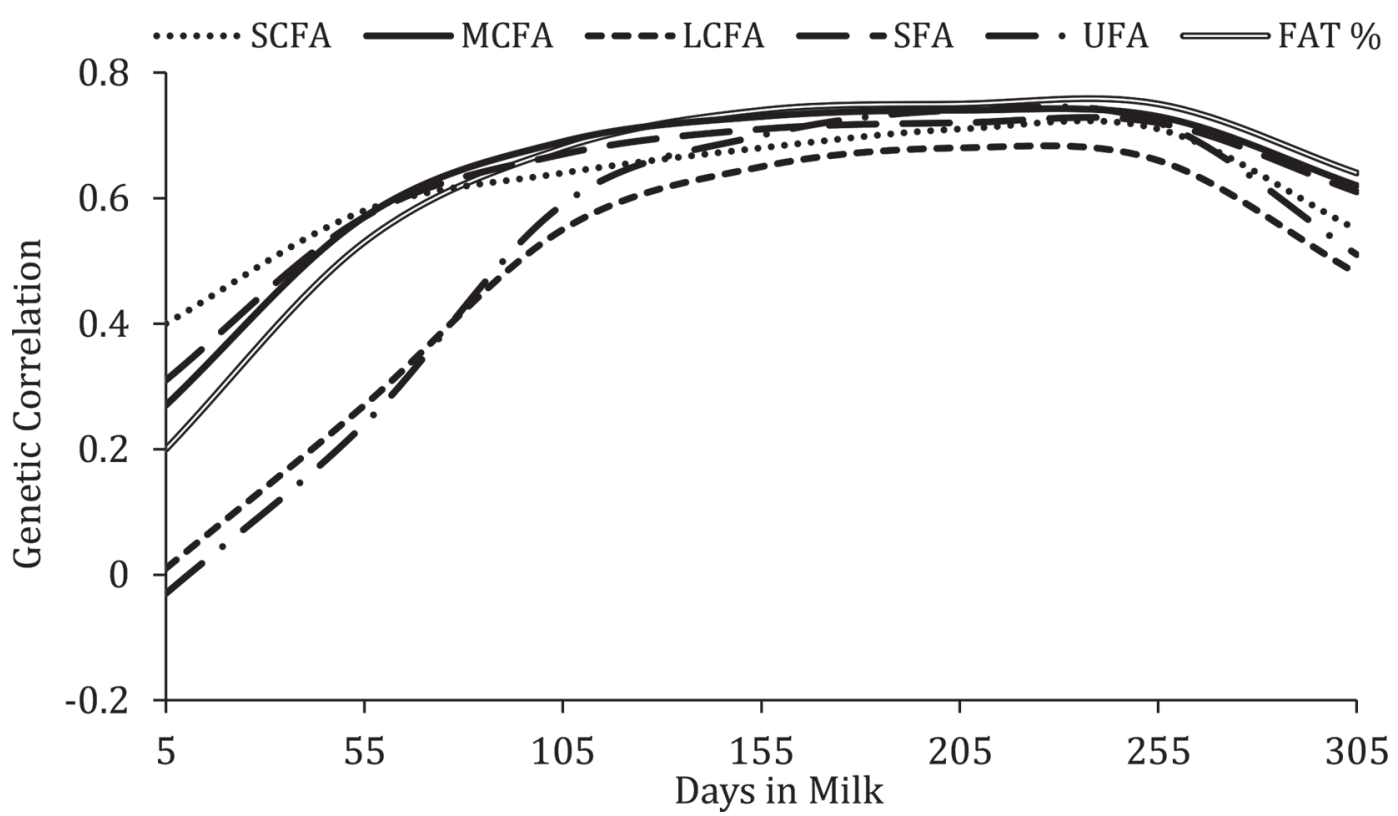

Figure 5. Daily genetic correlations for short-chain (SCFA), medium-chain (MCFA), long-chain (LCFA), SFA, and UFA groups and fat percentage (FAT \%) with protein percentage.

netic correlations were relatively constant through the lactation and only weakened marginally. At the beginning of lactation, the genetic correlations were stronger for LCFA and UFA than those observed for SCFA, MCFA, and SFA. The genetic correlations for SCFA, MCFA, and SFA continued to increase from 5 DIM until approximately 105 DIM, where they held steady until the end of lactation. The F:P of a milk sample has been proposed as an indicator of energy status in lactating dairy cows (Grieve et al., 1986), as have the fatty acid contents in the milk of the cow (Palmquist et al., 1993). Likewise, Koeck et al. (2013) reported a genetic correlation of 0.30 between $\mathrm{F}: \mathrm{P}$ and ketosis in the first 5 to 30 DIM for first-lactation Canadian

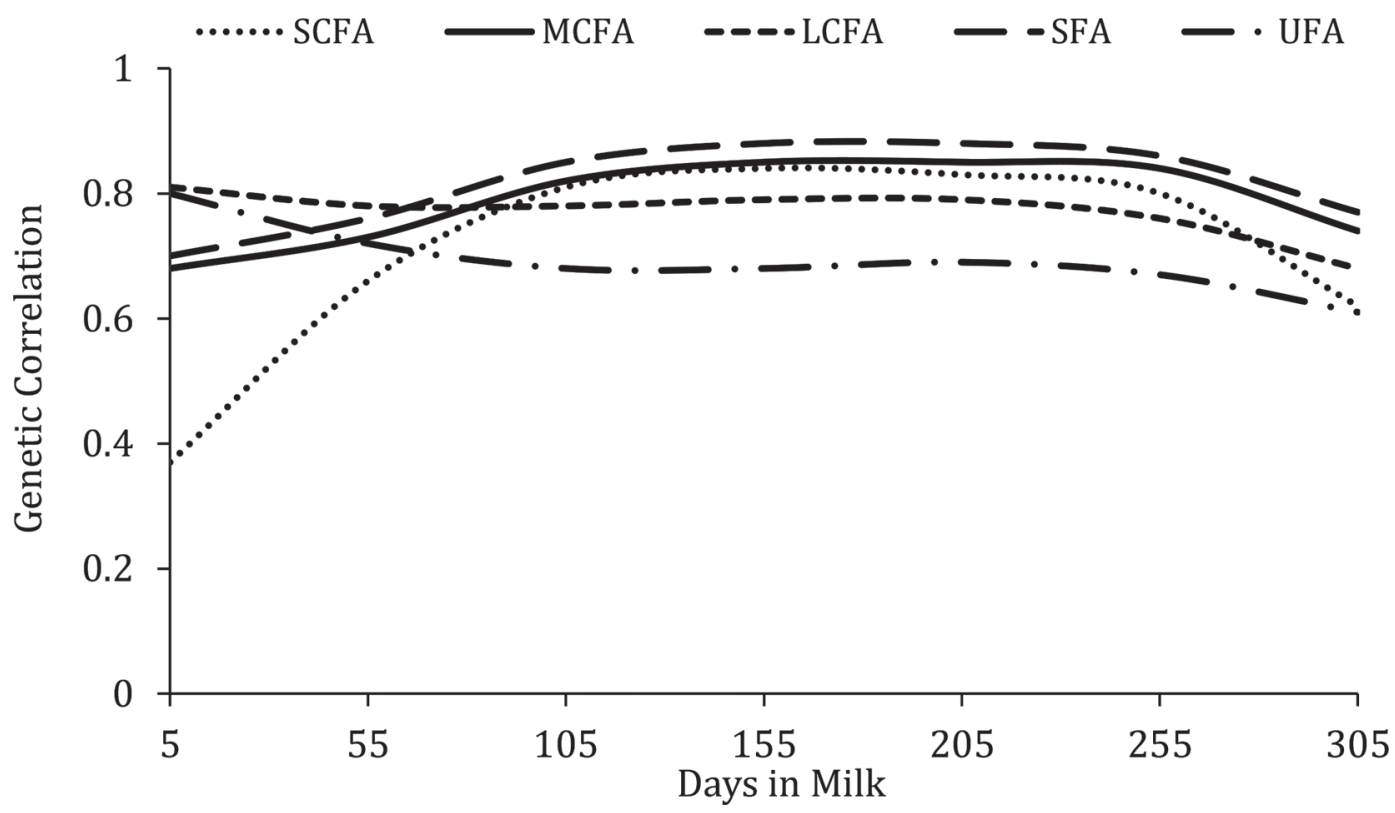

Figure 6. Daily genetic correlations for short-chain (SCFA), medium-chain (MCFA), long-chain (LCFA), SFA, and UFA groups with fatto-protein ratio. 
Holsteins. Therefore, the stronger genetic correlation at the beginning of lactation between the LCFA and SFA found in the current study may again relate to the physiological status of the cow in the initial stage of lactation.

The fatty acid groups all showed relatively similar patterns for genetic correlations with SCS across the lactation (Figure 7). Correlations were weak throughout the lactation but were the strongest at around 205 DIM for all fatty acids, and close to zero at both the beginning and end of lactation. Total fat percentage displayed the same trend and general magnitude as the fatty acid groups.

The inconsistencies in the genetic correlations across the lactation for fatty acids and production traits may aid in the setting of future selection goals related to fatty acid contents and be telling of how the milk fatty acid profile is affected by the current selection for production traits. For all of the production traits, except for fat yield, genetic correlations with fatty acid groups were the strongest in mid lactation. Fat yield, fat percentage, and F:P showed different patterns in genetic correlations with the different fatty acid groups in the important early stage of lactation. Selection for total fat at this point in the lactation may increase LCFA and UFA more compared with the other fatty acid groups. This is likely from cows able to increase the mobilization of body fat reserves, and thus care needs to be given to prevent cows with poor adaptation to negative energy balance and negative responses in cow health and reproduction traits. This brings forth some of the same concerns that may be true for breeding goals increasing LCFA and UFA in milk. An appraisal of the metabolic implications of increased fat mobilization and identification of cows able to handle such changes may be warranted.

If the entire lactation is considered, then SCFA, MCFA, and SFA are more strongly correlated with total fat traits and selecting for increased fat may increase the proportion of these fatty acids to a greater extent. Similarly, of the 5 fatty acid groups examined, MCFA and SFA also have the strongest average daily genetic correlations with protein percentage and F:P; therefore, these fatty acid groups could be more affected by selection for protein percentage and F:P. The comparable correlations for the fatty acid groups with milk and protein yield and SCS implies that selection for these traits will not have major implications for milk fatty acid contents.

In the present study, the examined fatty acid traits were expressed as a quantity in milk (grams per deciliter of milk). As discussed, this is the primary reason why the discovered genetic correlations were similar to each other and similar to total milk fat percentage. To decrease this relationship with fat percentage and to more effectively select for changes in the fatty acid profile, future studies should focus on the estimation of genetic correlations between the same production traits and fatty acids expressed on a per-fat basis (grams of fatty acid per weight of total milk fat). The effect of se-

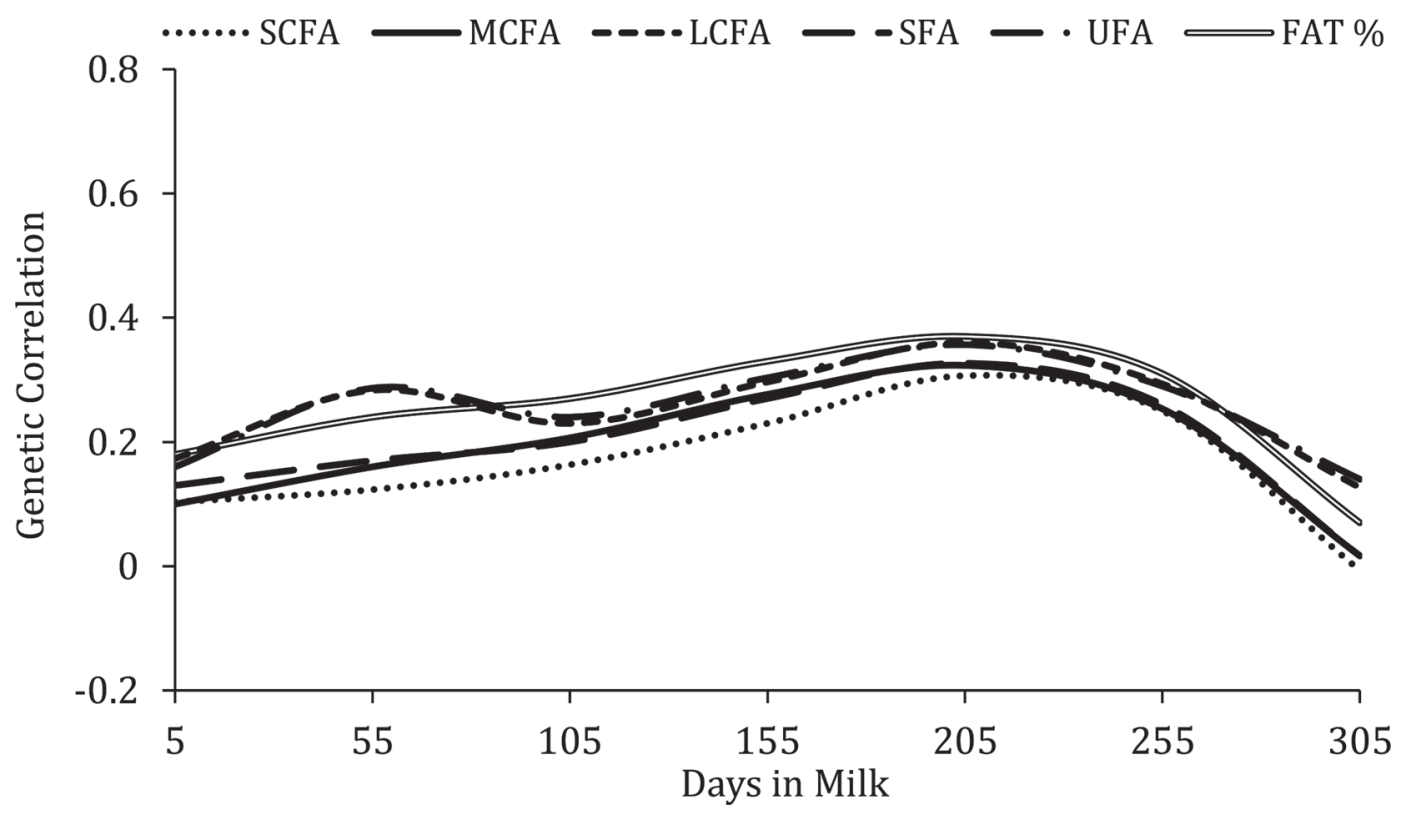

Figure 7. Daily genetic correlations for short-chain (SCFA), medium-chain (MCFA), long-chain (LCFA), SFA, and UFA groups averaged across the 3 analyses and fat percentage (FAT \%) with SCS. 
lection for any of the production traits on the fatty acid profile, or vice versa, may be more apparent with fatty acids on a per-fat basis. Genetic correlations between milk fatty acids on a per-fat basis and milk production traits have been previously examined by Karijord et al. (1982), Soyeurt et al. (2007), Stoop et al. (2008), Mele et al. (2009), and Bilal et al. (2014). Soyeurt et al. (2007) examined genetic correlations between fatty acids both on a milk basis and on a fat basis with production traits and found that, on a fat basis, greater differences exist in the genetic correlations between the different fatty acids with the production traits. For example, the reported genetic correlations with fat percentage were 0.76 and -0.22 for SFA and MUFA groupings, respectively. Stoop et al. (2008) found positive genetic correlations for SCFA and MCFA with fat percentage and negative correlations for LCFA and fat percentage. The same pattern was also noted between fatty acids and protein percentage as well as between fatty acids and fat yield. At present, one challenge of studying and selecting for fatty acids on a per-fat basis is the low accuracy of MIR predictions and achieving sufficient numbers of records for genetic evaluations.

As discussed, another consideration for this data set is the data structure present. Because of the limited number of test days with fatty acid records available, a result of randomness in the process of spectral data acquisition, the determined genetic parameters may be inappropriate for inference to the entire Canadian Holstein population. It will be imperative to re-estimate the genetic parameters of the fatty acid groups when test days across the whole lactation are available with fatty acid records for all milk-recorded cows.

\section{CONCLUSIONS}

Fatty acid contents in milk were found to be genetically correlated with production traits already evaluated in dairy breeding programs. Genetic correlations were strongest between fatty acid groups and fat percentage and similar in magnitude for all production traits. However, we noted differences between the fatty acid groups' genetic correlations with observed fat yield, fat and protein percentage, and F:P. Therefore, selection for these production traits could be inadvertently changing the contents of the groups of fatty acids to varying extents. Daily genetic correlations between fatty acids and production traits were not constant across the lactation. Trends in daily genetic correlations did differ for some production traits, and selection for these traits at various points in the lactation could affect milk fat composition differently. This is particularly true in early lactation for the correlation between fatty acid groups and fat yield and fat percentage traits, where
LCFA and UFA have stronger genetic correlations and energy balance of the cow could be a concern.

\section{ACKNOWLEDGMENTS}

All dairy producers participating in this project are gratefully acknowledged. We warmly acknowledge Ian Rumbles (now at DRPC, Raleigh, NC) and all the CanWest DHI team (Guelph, ON, Canada) as well as Daniel Lefebvre and the full team at Valacta (Ste-Annede-Bellevue, QC, Canada) for kindly organizing the selection of herds and collecting samples for the project. This study was partly funded by the DairyGen council of Canadian Dairy Network (Guelph, ON, Canada) and the Natural Sciences and Engineering Research Council of Canada (Ottawa, ON, Canada). This project is also partly supported by Agriculture and Agri-Food Canada and by additional contributions from Dairy Farmers of Canada, the Canadian Dairy Network and the Canadian Dairy Commission under the Agri-Science Clusters Initiative. We warmly acknowledge Foss (Hillerød, Denmark) for partial funding and technical support.

\section{REFERENCES}

Ali, A. K. A., and G. E. Shook. 1980. An optimum transformation for somatic cell concentration in milk. J. Dairy Sci. 63:487-490.

Bastin, C., N. Gengler, and H. Soyeurt. 2011. Phenotypic and genetic variability of production traits and milk fatty acid contents across days in milk for Walloon Holstein first-parity cows. J. Dairy Sci. 94:4152-4163.

Bastin, C., H. Soyeurt, and N. Gengler. 2013. Genetic parameters of milk production traits and fatty acid contents in milk for Holstein cows in parity $1-3$. J. Anim. Breed. Genet. 130:118-127.

Bilal, G., R. I. Cue, A. F. Mustafa, and J. F. Hayes. 2014. Short communication: Genetic parameters of individual fatty acids in milk of Canadian Holsteins. J. Dairy Sci. 97:1150-1156.

Bonfatti, V., A. Fleming, A. Koeck, and F. Miglior. 2017. Standardization of milk infrared spectra for the retroactive application of calibration models. J. Dairy Sci. 100:2032-2041.

Chilliard, Y., A. Ferlay, R. M. Mansbridge, and M. Doreau. 2000 Ruminant milk plasticity: Nutritional control of saturated, polyunsaturated, trans and conjugated fatty acids. Ann. Zootech. 49:181-205.

De Marchi, M., M. Penasa, A. Cecchinato, M. Mele, P. Secchiari, and G. Bittante. 2011. Effectiveness of mid-infrared spectroscopy to predict fatty acid composition of Brown Swiss bovine milk. Animal 5:1653-1658.

Fleming, A., F. S. Schenkel, J. Chen, F. Malchiodi, V. Bonfatti, R. A. Ali, B. Mallard, M. Corredig, and F. Miglior. 2017. Prediction of milk fatty acid content with mid-infrared spectroscopy in Canadian dairy cattle using differently distributed model development sets. J. Dairy Sci. 100:5073-5081.

Grieve, D. G., S. Korver, Y. S. Rijpkema, and G. Hof. 1986. Relationship between milk composition and some nutritional parameters in early lactation. Livest. Prod. Sci. 14:239-254.

Ingvartsen, K. L., R. J. Dewhurst, and N. C. Friggens. 2003. On the relationship between lactational performance and health: Is it yield or metabolic imbalance that cause production diseases in dairy cattle? A position paper. Livest. Prod. Sci. 83:277-308.

Jamrozik, J., L. R. Schaeffer, and K. A. Weigel. 2002. Estimates of genetic parameters for single- and multiple-country test-day models. J. Dairy Sci. 85:3131-3141. 
Jorjong, S., A. T. M. van Knegsel, J. Verwaeren, R. M. Bruckmaier, B. De Baets, B. Kemp, and V. Fievez. 2015. Milk fatty acids as possible biomarkers to diagnose hyperketonemia in early lactation. J. Dairy Sci. 98:5211-5221.

Jorritsma, R., T. Wensing, T. A. M. Kruip, P. L. A. M. Vos, and J. P. T. M. Noordhuizen. 2003. Metabolic changes in early lactation and impaired reproductive performance in dairy cows. Vet. Res. $34: 11-26$

Karijord, Ø., N. Standal, and O. Syrstad. 1982. Sources of variation in composition of milk fat. Z. Tierzuecht. Zuechtungsbiol. 99:81-93.

Kliem, K. E., and K. J. Shingfield. 2016. Manipulation of milk fatty acid composition in lactating cows: Opportunities and challenges. Eur. J. Lipid Sci. Technol. 118:1661-1683.

Koeck, A., F. Miglior, J. Jamrozik, D. F. Kelton, and F. S. Schenkel. 2013. Genetic associations of ketosis and displaced abomasum with milk production traits in early first lactation of Canadian Holsteins. J. Dairy Sci. 96:4688-4696.

Loker, S., C. Bastin, F. Miglior, A. Sewalem, L. R. Schaeffer, J. Jamrozik, A. Ali, and V. Osborne. 2012. Genetic and environmental relationships between body condition score and milk production traits in Canadian Holsteins. J. Dairy Sci. 95:410-419.

Mele, M., R. Dal Zotto, M. Cassandro, G. Conte, A. Serra, A. Buccioni, G. Bittante, and P. Secchiari. 2009. Genetic parameters for conjugated linoleic acid, selected milk fatty acids, and milk fatty acid unsaturation of Italian Holstein-Friesian cows. J. Dairy Sci. 92:392-400.

Miglior, F., A. Sewalem, J. Jamrozik, J. Bohmanova, D. M. Lefebvre, and R. K. Moore. 2007. Genetic analysis of milk urea nitrogen and lactose and their relationships with other production traits in Canadian Holstein cattle. J. Dairy Sci. 90:2468-2479.

Narayana, S. G., F. S. Schenkel, A. Fleming, A. Koeck, F. Malchiodi, J. Jamrozik, J. Johnston, M. Sargolzaei, and F. Miglior. 2017. Genetic analysis of groups of mid-infrared predicted fatty acids in milk. J. Dairy Sci. 100:4731-4744.

Palmquist, D. L., A. D. Baulieu, and D. M. Barbano. 1993. Feed and animal factors influencing milk fat composition. J. Dairy Sci. $76: 1753-1771$.
Parodi, P. 2004. Milk fat in human nutrition. Aust. J. Dairy Technol. $59: 3-59$.

Pegolo, S., A. Cecchinato, J. Casellas, G. Conte, M. Mele, S. Schiavon, and G. Bittante. 2016. Genetic and environmental relationships of detailed milk fatty acids profile determined by gas chromatography in Brown Swiss cows. J. Dairy Sci. 99:1315-1330.

Penasa, M., F. Tiezzi, P. Gottardo, M. Cassandro, and M. De Marchi. 2015. Genetics of milk fatty acid groups predicted during routine data recording in Holstein dairy cattle. Livest. Sci. 173:9-13.

Pryce, J. E., M. D. Royal, P. C. Garnsworthy, and I. L. Mao. 2004 Fertility in the high-producing dairy cow. Livest. Prod. Sci. $86: 125-135$

Rutten, M. J. M., H. Bovenhuis, K. A. Hettinga, H. J. F. van Valenberg, and J. A. M. van Arendonk. 2009. Predicting bovine milk fat composition using infrared spectroscopy based on milk samples collected in winter and summer. J. Dairy Sci. 92:6202-6209.

Soyeurt, H., P. Dardenne, F. Dehareng, G. Lognay, D. Veselko, M. Marlier, C. Bertozzi, P. Mayeres, and N. Gengler. 2006. Estimating fatty acid content in cow milk using mid-infrared spectrometry. J. Dairy Sci. 89:3690-3695.

Soyeurt, H., A. Gillon, S. Vanderick, P. Mayeres, C. Bertozzi, and N. Gengler. 2007. Estimation of heritability and genetic correlations for the major fatty acids in bovine milk. J. Dairy Sci. 90:44354442.

Stoop, W. M., H. Bovenhuis, J. M. L. Heck, and J. A. M. van Arendonk. 2009. Effect of lactation stage and energy status on milk fat composition of Holstein-Friesian cows. J. Dairy Sci. 92:1469-1478.

Stoop, W. M., J. A. M. van Arendonk, J. M. L. Heck, H. J. F. van Valenberg, and H. Bovenhuis. 2008. Genetic parameters for major milk fatty acids and milk production traits of Dutch HolsteinFriesians. J. Dairy Sci. 91:385-394.

van Gastelen, S., and J. Dijkstra. 2016. Prediction of methane emission from lactating dairy cows using milk fatty acids and midinfrared spectroscopy. J. Sci. Food Agric. 96:3963-3968.

Wood, G. M., P. J. Boettcher, J. Jamrozik, G. B. Jansen, and D. F. Kelton. 2003. Estimation of genetic parameters for concentration of milk urea nitrogen. J. Dairy Sci. 86:2462-2469. 